\title{
Evaluation of In-Use Fuel Economy for Hybrid and Regular Transit Buses
}

\author{
Shauna L. Hallmark, Bo Wang, Yu Qiu, Robert Sperry \\ Iowa State University, Ames, USA \\ Email: shallmar@iastate.edu
}

Received October 9, 2012; revised November 10, 2012; accepted November 24, 2012

\begin{abstract}
Fuel costs are a significant portion of transit agency budgets. Hybrid technology offers an attractive option and has the potential to significantly reduce operating costs for agencies. The main impetus behind use of hybrid transit vehicles is fuel savings and reduced emissions. Laboratory tests have indicated that hybrid transit buses can have significantly higher fuel economy and lower emissions compared to conventional transit buses. However, the number of studies is limited and laboratory tests may not represent actual driving conditions since in-use vehicle operation differs from laboratory test cycles. Several initial studies have suggested that the fuel economy savings reported in laboratory tests may not be realized on-road. The objective of the project described in this paper was to evaluate the in-use fuel economy differences between hybrid-electric and conventional transit buses for the Ames, Iowa (USA) transit authority. On-road fuel economy was evaluated over a 12-month period for 12 hybrid and 7 control transit buses. Fuel economy comparisons were also provided for several older in-use bus types. Buses other than the control and hybrid buses were grouped by model year corresponding to US diesel emission standards. Average fuel economy in miles per gallon was calculated for each bus group overall and by season. Hybrid buses had the highest fuel economy for all time periods for all bus types. Hybrid buses had a fuel economy that was $11.8 \%$ higher than control buses overall and was $12.2 \%$ higher than buses with model years 2007 and higher, 23.4\% higher than model years 2004 to 2006, 10.2\% higher than model years 1998 to 2003, 38.1\% higher than for model years 1994 to 1997, 36.8\% higher for model years 1991 to 1993, and $36.8 \%$ higher for model years pre-1991. Differences between groups of buses also varied by season of the year.
\end{abstract}

Keywords: Hybrid Vehicle; Fuel Economy; Transit

\section{Introduction}

Fuel costs are a significant portion of transit agency budgets. Hybrid buses offer an attractive option and have the potential to significantly reduce operating costs for agencies. Hybrid technology has been available in the transit market for some time. There are over 1200 hybrid buses in regular service in North America in over 40 transit agencies as of 2009 [1]. The majority are regular 40 -foot buses although some smaller (20-foot) shuttle buses and larger articulated (60-foot) buses are also in service.

Hybrid technology offers an attractive option and has the potential to significantly reduce operating costs for agencies. The main impetus behind use of hybrid transit vehicles is fuel savings and reduced emissions. Wayne $e t$ al [2] estimated that use of diesel-electric hybrid buses in $15 \%$ of the US transit fleet could reduce fuel consumption by 50.7 million gallons of diesel annually.

However, purchase of hybrid transit buses requires a significant investment for transit agencies since a hybrid bus costs approximately $50 \%$ to $70 \%$ more than a con- ventional diesel transit bus [3]. Additionally, early estimates of fuel savings were based on laboratory studies which demonstrated significant fuel savings and actual in-use savings may not have may not have materialized to the extent transit agencies expected.

\section{Background}

Laboratory tests in general have indicated that the fuel economy of hybrid transit buses is significantly better than for regular buses. Chassis dynamometer tests were conducted for 10 low-floor hybrid buses and 14 conventional high-floor diesel transit buses run by New York City Transit [4]. Buses were evaluated over three driving cycles including the Central Business District (CBD), New York bus cycle, and the Manhattan cycle. The operating costs, efficiency, emissions, and overall performance were also compared while both types of buses were operating on similar routes. They found that fuel economy was $48 \%$ higher for the hybrid buses.

A study by Battelle [5] tested emissions using a dynamometer for one diesel hybrid-electric bus and two regular 
diesel buses (with and without catalyzed diesel particulate filters [DPF]). The researchers reported that fuel economy for the hybrid bus was 54\% higher than the two regular diesel buses. In another study, two buses were tested using a dynamometer at the National Renewable Energy Laboratory's (NREL's) Refuel facility in Golden, Colorado [4]. One bus was a conventional diesel and the other was a hybrid bus and both were tested over several drive cycles including Manhattan, Orange County Transit A (OCTA), CBD, and King County Metro (KCM). Results indicate $30.3 \%$ lower fuel use for the KCM cycle, 48.3\% lower for the CBD cycle, 50.6\% for the OCTA cycle, and $74.6 \%$ for the Manhattan cycle. Fuel economy was reported in miles per gallon (mpg).

In another study, Clark et al. [6] evaluated six transit buses with traditional diesel engines, two powered by spark-ignited compressed natural gas (CNG), and one hybrid transit bus in Mexico City using a mobile heavyduty emissions testing lab. Buses were tested over a driving cycle representative of Mexico City transit bus operation, which was developed using GPS data from in-use transit buses. Depending on how fuel economy was evaluated, the hybrid bus ranked 4th and 1st in fuel economy.

Transport Canada [1] summarized several studies which compared fuel economy for several transit agencies in Canada. In one laboratory study, using the Manhattan Test Cycle, a reduction in fuel consumption of $36 \%$ resulted for hybrid buses as compared to regular buses. Results of a test track study showed a $28 \%$ fuel reduction for hybrid transit buses compared to regular buses when the buses were operated at an average speed of $10 \mathrm{~km} / \mathrm{h}$ with 10 stops per kilometer. As average speed increased the differences in fuel consumption were smaller.

Barnitt and Gonder [7] collected school bus drive cycle data for a first-generation PHEV school bus and a conventional school bus. Both were tested over several different driving cycles to represent a range of driving activity. When in charge-depleting mode, the PHEV had a fuel savings of more than 30\% for the Ruban Dynamometer Driving Schedule for Heavy Duty Vehicles and Rowan University Composite School Bus drive cycles. Fuels savings of over 50\% were noted for the hybrid school bus for the Orange County Bus cycle. When in charge sustaining mode, smaller fuel savings were noted.

As noted, many of the studies which have demonstrated significant improvements in fuel economy were based on laboratory studies. Fuel economy varies and is correlated to a number of factors, including number of stops per unit distance, road grade, surrounding traffic volume and conditions, environmental conditions, driving style, type of hybrid technology (parallel versus series) [8], roadway type, and passenger load [9]. As a re- sult, actual in-use fuel economy may vary from what has been reported for laboratory studies.

A few studies are available which have evaluated in-use fuel economy for hybrid transit vehicles. Transport Canada [1] reported that the Toronto Transit Corporation which has around 500 hybrid buses was only achieving a reduction of $10 \%$ for in-use fuel consumption. The Federal Transit Administration [10] published a report on the status, current issues, and benefits of hybrid bus technology. They summarized the experiences from four transit agencies in the US and found the hybrid buses had better fuel efficiency, accelerating, and handling experience. The overall fuel economy increases for New York, Cedar Rapids, and Los Angeles transit agencies were $18 \%$, 15\%, 5\% respectively. However, these values were significantly lower than fuel economy estimates which have been reported in laboratory studies.

In a related study, Hallmark et al. [11] evaluated two plug-in hybrid-electric school buses and 2 regular school buses. They found that fuel economy was $29.6 \%$ and $39.2 \%$ higher for the hybrid buses than the control buses.

\section{Project Objectives}

Laboratory few tests have indicated that hybrid transit buses can have significantly higher fuel economy compared to conventional transit buses. However, the number of studies is limited and laboratory tests may not represent actual driving conditions since in-use vehicle operation differs from laboratory test cycles. Several initial studies have suggested that the fuel economy savings reported in laboratory tests may not be realized on-road.

This report summarizes the results of a study which evaluated fuel economy for 12 hybrid transit and 7 control buses which are part of the Ames Transit Agency, CyRide. Ames is a community with a population of almost 60,000 and is located in the state of Iowa, a Midwestern state in the US.

The fuel economy of the hybrid buses was compared to a set of buses with similar characteristics. Fuel economy comparisons were also provided for several older in-use bus types. This information is important because CyRide needed to compare the impact of the hybrid buses compared to the buses they replaced.

\section{Study Background}

CyRide, the city bus system for Ames, Iowa, is operated through collaboration between the city and Iowa State University (ISU). CyRide reported 5,447,289 passengers for fiscal year 2011 and posted 1,185,089 revenue miles [12].

CyRide regularly operates around 79 buses and purchased 12 hybrid transit buses using a Transit Investments for Greenhouse Gas and Energy Reduction (TIGGER) 
grant. In addition to the 12 hybrid buses, 7 regular diesel buses were selected from among the regular diesel buses in the CyRide fleet. These control buses were selected since they had similar bus specifications in terms of manufacture, model year, and engine size as the hybrid buses as shown in Table 1. Fuel economy was also tracked for other buses in the CyRide fleet although they vary in characteristics. Comparison to other buses was done so that CyRide could compare the hybrids to the rest of their fleet as well as assess how much improvement was gained over buses that were replaced by the hybrid buses.

Other buses were grouped into model years corresponding to US diesel emission standards since engines from years with the same standards would have similar emission control technology which can affect fuel consumption. US diesel engine standards cover 1991-1993, 1994-1997, 1998-2003, and 2004-2006, and 2007 and higher [13]. Buses were included in the analysis if they were operated for the majority of a season. Several buses were only used for a very limited period during the analysis period and were not included in the analysis. Other bus types are shown in Table 2.

CyRide operates with 12 fixed routes. The fixed routes operate every day of the year except Thanksgiving, Christmas, and New Year's Day. CyRide rotates buses into and off the system to meet peak travel demands. Buses are driven over several routes according to a prescribed schedule (route pattern), depending on when the bus comes into and leaves the system. Drivers are typically assigned to a route pattern. In general the buses are randomly cycled through the various route patterns. As a result, it was assumed that buses were randomly deployed across routes and any individual bus was equally likely to be assigned to a particular route and driver. Consequently it was assumed that over time, differences due to route, driver characteristics, and passenger loading were minimized.

The hybrid-electric buses were in use by Fall 2010. Initially CyRide was not finding that the hybrid buses were performing as well as expected. The hybrid buses were the first ones in production and as a result experi-

Table 1. Specifications of both hybrid diesel buses and conventional diesel buses.

\begin{tabular}{lll}
\hline & Hybrid Diesel Buses & Conventional Diesel Buses \\
\hline Bus Number & $118,119,120,121,122,123,124,429,430, \& 431$ & $819,820,821,822,126,127, \& 128$ \\
Capital Cost & 2010 & $2008 / 2010$ \\
Manufacture & $\$ 521,970$ & $\$ 367,115$ \\
Bus Type & Gillig Hybrid & Gillig \\
Engine & Low Floor & Low Floor \\
Transmission & Cummins '10 ISL 280 HP, & Cummins '10 ISL 280 HP, \\
After treatment & in line six cylinders & in line six cylinders \\
Governed Speed & Poith DIWA Parallel Hybrid & Voith D864.5 4-speed \\
Start Date & 65 mph & Particular Filter (CPF) \\
Frontal Area & $6 / 28 / 2010$ & 65 mph \\
Length $\times$ Height & $113.5 \times 102 \mathrm{ft}$ & $6 / 28 / 2010$ \\
Curb Weight & $40 \mathrm{ft} \times 138$ in & $113.5 \times 102 \mathrm{ft}$ \\
\hline
\end{tabular}

Table 2. Specifications for other buses tracked for fuel economy.

\begin{tabular}{lcl}
\hline Standard Year & Number of Buses & Bus Types \\
\hline Pre-1991 & 7 & GMC-1973; Orion V-1989 \\
1991 to 1993 & 6 & Gillig Phantom-1993 \\
1994 to 1997 & 7 & Gillig Phantom-1996; Gillig Phantom-1997 \\
1998 to 2003 & 18 & Gillig Lowfloor-1999; Orion V—2000; Orion V—2002 \\
2004 to 2006 & 12 & Gillig Lowfloor-2008; Orion V—2005; Orion VII—2006 \\
\hline
\end{tabular}


enced some early issues. Consequently, the manufacturer made several adjustments to the brake pedals and made programming adjustments. The first adjustments made in early summer 2011 to fix the brake pedals, which directly affects the capture of regenerative energy. Programming was conducted to increase fuel economy. The team collected data prior to July 2011 but since fairly significant changes had occurred, they did not include that data in the final analysis.

\section{Data Collection}

CyRide buses are usually fueled at the end of their service day when they return to the garage. Each time a bus is fueled is referred to as a fueling period. CyRide technicians note the amount of fuel used (in gallons) and the odometer reading for each fueling period. Differences in odometer readings between fueling periods represents the operating mileage during the period between fueling which in most cases was one day. CyRide uses an average of a $2 \%$ blend of bio-diesel. Buses are all fueled from the same tank.

Fuel and odometer data were provided to the team weekly or bi-weekly in a hard copy format. Data were entered into a spreadsheet with date, bus number, fuel used, and odometer reading. One row of data represents on fueling period. Data were manually entered by fueling period by bus. Consequently each row of data (observation) was one fueling period for a one particular bus. Data were collected and entered for 50 buses. This resulted in 5746 fueling periods (observations) for the one-year analysis period.

Data were reviewed to ensure data quality. Outliers were identified and if they appear to be erroneous data, were removed. For instance, odometer readings or fuel economy that clearly did not make sense were removed.

Since environmental conditions can impact fuel economy, weather was approximated by using season of the year. Quarters were designated using the following convention, which aggregates months where weather conditions were the most likely to be similar in Iowa:

- Winter (December, January, February);

- Spring (March, April, May);

- Summer (June, July, August);

- Fall (September, October, November).

\section{Analysis and Resutls}

In addition to the hybrid and control buses, other buses were grouped by model year corresponding to US diesel standards as shown in Table 2. Data were further disaggregated by season. Fuel economy (in miles per gallon \{mpg\}) for each observation was calculated by using Equation (1):

$$
F E_{i}=m_{i} / F_{i}
$$

where:

$F E_{i}=$ fuel economy in miles per gallon for fueling interval $i$,

$m_{i}=$ miles driven during fueling period $i$,

$F_{i}=$ fuel used for fueling period $i$.

Average fuel economy was calculated for each bus group overall and by season. Results are shown in Figure 1. Average fuel economy by bus group by season is shown along with the standard error. Results were also compared using a t-test. Standard error was calculated using Equation 2. Standard error is shown as error bars in Figures 1 and 2.

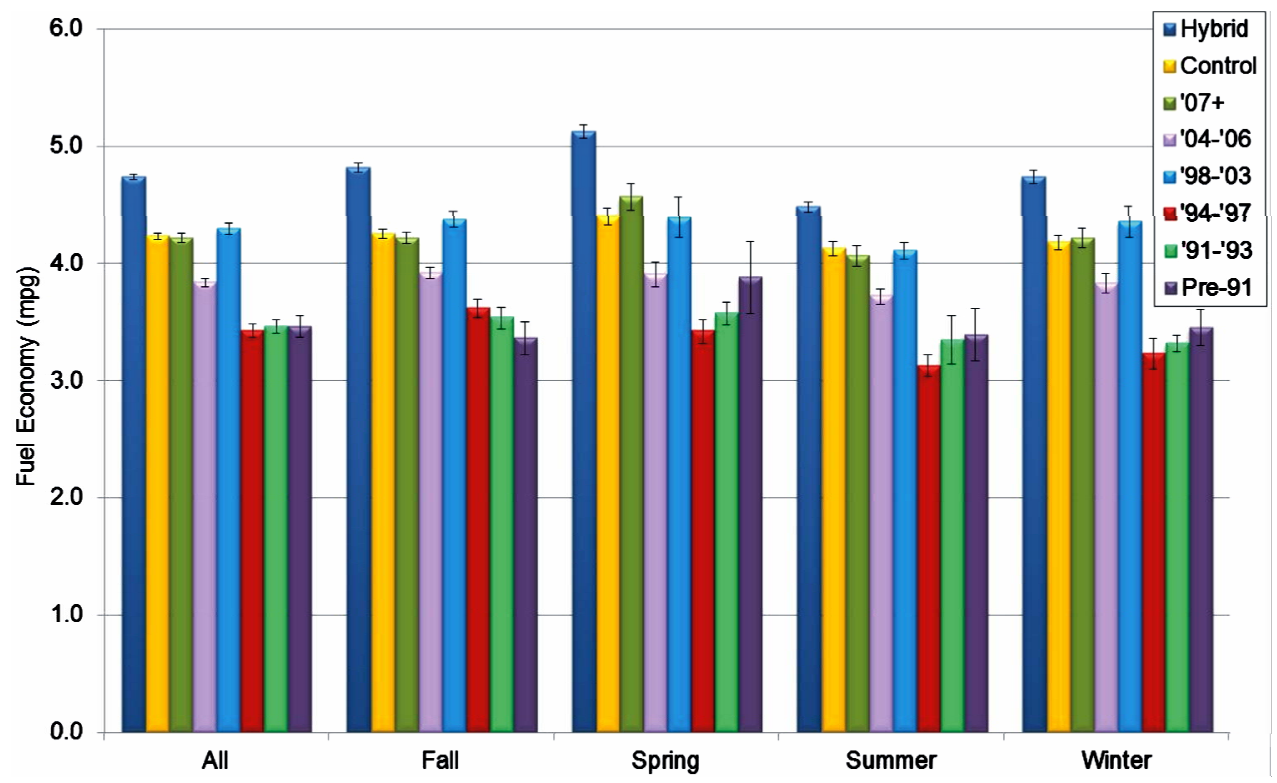

Figure 1. Average fuel economy (mph) by season by bus group. 


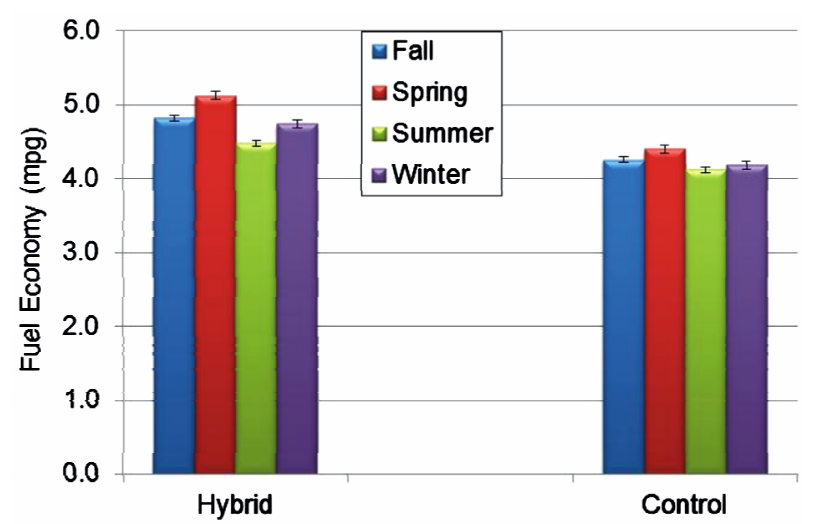

Figure 2. Fuel economy for hybrid and control buses by season.

$$
S E=\frac{S}{\sqrt{N}}
$$

As shown, hybrid buses had the highest fuel economy for all time periods combined. Hybrid buses had a fuel economy that was $11.8 \%$ higher than control buses ( $\mathrm{p}<<$ 0 ) for all times periods and was $12.2 \%$ higher than buses with model years 2007 and higher ( $\mathrm{p}<<0$ ), 23.4\% higher than model years 2004 to 2006 ( $p<<0$ ), 10.2\% higher than model years 1998 to 2003 ( $p<<0$ ), 38.1\% higher than for model years 1994 to 1997 ( $p<<0$ ), 36.8\% higher for model years 1991 to 1993 (p $<<0$ ), and 36.8\% higher for model years pre-1991 ( $\mathrm{p}<<0)$.

Differences between groups of buses also varied by season. The hybrid bus had average fuel economy that was $1.3 \%$ higher than control buses for fall $(\mathrm{p}<<0)$, $16.4 \%$ higher for spring ( $\mathrm{p}<<0$ ), 8.6\% higher for summer ( $\mathrm{p}<<0$ ), and 13.3\% higher for winter ( $\mathrm{p}<<0)$. Fuel economy was highest for almost all bus types in the spring. Additionally, as shown average fuel economy was lower in the summer for most bus types than for the other seasons. In most cases, fuel economy was highest in the spring

Fuel economy was compared by season as shown in Figure 2 for hybrid buses. Fuel economy was highest in the spring (4.8 $\mathrm{mpg}$ ) and lowest in the summer (4.5 mpg). Fuel economy was $6.3 \%$ higher in the spring than fall ( $p$ $<<0$ ), $14.4 \%$ higher in the spring than in the summer (p $<<0$ ), and $8.1 \%$ higher for spring than winter ( $\mathrm{p}<<0)$. Fuel economy was $7.6 \%$ higher in the fall than summer $(\mathrm{p}<<0)$ and $1.7 \%$ higher in the fall than winter although the difference was not statistically significant $(\mathrm{p}=0.116)$. Finally fuel economy was $5.7 \%$ higher for the winter than summer $(p=0.0001)$.

Similar results were found for control buses as shown in Figure 2. However differences between seasons were less pronounced than for the hybrid buses. The highest fuel economy occurred in the spring and the lowest fuel economy occurred in the summer $(6.7 \%$ higher, $\mathrm{p}=$
0.0014). Fuel economy was also higher in the spring than in the fall (3.5\% higher, $\mathrm{p}=0.0315)$ and winter $(5.3 \%$ higher, $p=0.009$ ). Similarly fall has the next highest fuel economy by season for the control buses and was 3.1\% higher than summer $(p=0.038)$ and $1.7 \%$ higher than winter ( $p=0.157)$ although the difference is not statistically significant. Wintertime fuel economy is $1.3 \%$ higher than summer ( $p=0.744)$ but the difference is not statistically significant.

\section{Summary}

Hybrid transit wbuses require a significant investment for transit agencies with purchase price currently being approximately $50 \%$ to $70 \%$ higher than a conventional diesel bus. Early estimates of cost savings may not have materialized to the extent transit agencies expected. In order to justify the expenditure, agencies require more quantitative information about the on-road fuel economy for hybrid buses.

In-use fuel economy differences were compared for hybrid-electric and conventional transit buses for the Ames, Iowa (USA) transit authority, CyRide. On-road fuel economy was evaluated over a 12-month period for the 12 hybrid transit and 7 control buses. The hybrid diesel buses are 2010 Gillig low floor buses with $280 \mathrm{HP}$ and in line six cylinders. The control buses are 2008/ 2010 Gillig low floor diesel buses also with 280 HP and in line six cylinders. Fuel economy comparisons were also provided for several older bus types. Buses other than the control and hybrid buses were grouped by model year corresponding to US diesel standards.

Average fuel economy in miles per gallon was calculated for each bus group overall and by season. A total of 5,746 observations were available for the 12 month analysis period.

Hybrid buses had the highest fuel economy for all time periods for all bus types. Hybrid buses had a fuel economy that was $11.8 \%$ higher than control bus overall and was $12.2 \%$ higher than buses with model years 2007 and higher, 23.4\% higher than model years 2004 to 2006, 10.2\% higher than model years 1998 to 2003, 38.1\% higher than for model years 1994 to 1997, 36.8\% higher for model years 1991 to 1993, and 36.8\% higher for model years pre-1991. Differences were statistically significant.

Fuel economy for the hybrid buses was highest in the spring at $4.8 \mathrm{mpg}$ and lowest in the summer at $4.5 \mathrm{mpg}$ (14.4\% higher). Fuel economy for the hybrid buses was 6.3\% higher in the spring than fall and $8.1 \%$ higher for spring than winter. Fuel economy was $7.6 \%$ higher in the fall than summer and $1.7 \%$ higher in the fall than winter although the difference was not statistically significant. Finally fuel economy was $5.7 \%$ higher for the winter than summer. 
Fluctuations were slightly higher over season for the hybrid versus control buses. This may be due to power requirements for heating and air condition.

Similar results were found for other bus types with the highest fuel economy in the spring and lowest in the summer.

Overall, hybrid buses reported fuel economy that was around $12 \%$ higher than for similar control buses. This is similar to results found from other in-use studies which have reported fuel economy improvements from $5 \%$ to $18 \%$. These estimates are somewhat lower than the estimates from laboratory studies which have shown improvements of $30 \%$ to $75 \%$.

\section{Study Limitations}

Fuel economy is highly correlated to vehicle operation (amount of time spent in a particular speed/acceleration range). Fuel economy is also related to vehicle load (number of passengers). Ideally, the study would have collected instantaneous fuel economy and vehicle operation by instrumenting vehicles. This type of data could have been collected for a short analysis period; however, it was felt that tracking the buses over a longer period of time was more representative of in-use fuel economy. Additionally, it was not within project resources to instrument buses and collect and reduce these data daily over a 12-month period.

The team did attempt to collect passenger load. However, CyRide only collects total passengers who utilized a particular bus on a daily basis (no information about where passengers embark or disembark). As a result, collection of passenger load would require data collectors to be present on the buses, which was not feasible.

Since CyRide does rotate buses over route patterns, it was assumed that buses would randomly be assigned over all route patterns over time. Since each route has similar drivers, route characteristics and passenger loading, rotation across routes would minimize differences. The team acknowledges that this is not a perfect solution and assumes no bias on the part of CyRide in assigning buses. Additionally it cannot account for daily differences in traffic operations and ridership. These issues, however, are inherent with any large scale, uncontrolled data collection study. And the team feels that collection of the data in-use does provide valuable information to transit agencies that are likely to compare differences in a similar manner.

\section{Acknowledgements}

The team would like to thank the Iowa Energy Center for funding this project. We would also like to thank CyRide for all of their assistance in giving feedback, providing data, and allowing us to conduct the study. In particular we would like to thank Sheri Kyras, James Rendall, Rich
Leners, and all of the technicians who provided data for their assistance.

\section{REFERENCES}

[1] Transport Canada, "Hybrid Buses,” 2011. http://www.tc.gc.ca/eng/programs/environment-utsp-case study-cs71e-hybridbuses-272.htm

[2] S. W. Wayne, J. A. Sandoval and N. N. Clark, "Emission Benefits from Alternative Fuels and Advanced Technology in the US Transit Bus Fleet," Energy and Environment. Vol. 20, No. 4, 2009, pp. 497-515. doi:10.1260/095830509788707374

[3] Hybrid Center, "Hybrid Watchdog: Hybrid Transit Buses Are They Really Green?” 2010. http://www.hybridcenter.org/hybrid-transit-buses.html

[4] K. Chandler and K. Walkowicz, "King County Metro Transit Hybrid Articulated Buses: Final Evaluation Report,” Technical Report NREL/TP-540-40585, National Renewable Energy Laboratory, Golden City, 2006.

[5] Battelle, "Technical Assessment of Advanced Transit Bus Propulsion Systems,” Dallas Area Rapid Transit, Dallas, 2002.

[6] N. N. Clark, E. R. Borrell, D. L. McKain, V. H. Paramo, W. S. Wayne, W. Vergara, R. A. Barnett, M. Gautam, G. Thompson, D. W. Lyons and L. Schipper, "Evaluation of Emissions from New and In-Use Transit Buses in Mexico City, Mexico," Journal of the Transportation Research Record, Vol. 1987, 2006, pp. 42-53. doi:10.3141/1987-05

[7] R. A. Barnitt and J. Gonder, "Drive Cycle Analysis, Measurements of Emissions and Fuel Consumption of a PHEV School Bus,” The SAE 2011 World Congress, Detroit, 12-14 April 2011, 13 p.

[8] X. Liang, C. Wang, C. Chapelsky, D. Koval and A. M. Knight, "Analysis of Series and Parallel Hybrid Bus Fuel Consumption of Different Edmonton Transit System Routes," 5th IEEE Vehicle Power and Propulsion Conference, VPPC '09, 7-10 September 2009, Dearborn, pp. 1470-1475.

[9] H. C. Frey, N. M. Rouphail, H. Zhai, T. L. Farias and C. A. Goncalves, "Comparing Real-World Fuel Consumption for Diesel and Hydrogen-Fueled Transit Buses and Implications for Emissions," Transportation Research Part D: Transport and Environment, Vol. 12, No. 4, 2007, pp. 281-291. doi:10.1016/j.trd.2007.03.003

[10] Federal Transit Administration, "Hybrid-Electric Transit Buses: Status, Issues, and Benefits,” TCRP Report 59, Transportation Research Board, Washington DC, 2000.

[11] S. Hallmark and R. Sperry, "Comparison of In-Use Operating Costs of Hybrid-Electric and Conventional School Buses," Journal of Transportation Technologies, Vol. 2, No. 2, 2012, pp. 158-164. doi:10.4236/jtts.2012.22017

[12] CyRide, “Statistics,” 2012. http://www.cyride.com/index.aspx?page $=1240$

[13] US Emission Standards Reference Guide (USEPA), "Heavy-Duty Highway Compression-Ignition Engines and Urban Buses_Exhaust Emission Standards,” 2012. http://www.epa.gov/otaq/standards/heavy-duty/hdci-exha ust.htm 